\title{
Pembangunan Web E-Commerce B2B Untuk Meningkatkan Pemasaran dan Penjualan Produk Menggunakan Linear Sequential Model
}

\author{
Susafaati $^{1}$, Nunung Hidayatun ${ }^{2}$, Hidayanti Murtina ${ }^{3}$ \\ ${ }^{1,3}$ STMIK Nusa Mandiri Jakarta/Teknik Informatika \\ e-mail: susafaati.suf@nusamandiri.ac.id; hidayantimurtina@gmail.com \\ ${ }^{2}$ Universitas Bina Sarana Informatika/Sistem Informasi \\ e-mail: nunung.ntn@bsi.ac.id
}

\begin{abstract}
Abstraksi - Internet menyebabkan berkembangnya aktivitas perdagangan yaitu dengan adanya penjualan produk secara online, fasilitas ini disebut dengan e-commerce. PT. Victoria Label adalah perusahaan PMA (Penanaman Modal Asing) yang bergerak di bidang pembuatan label tenun dan label cetak (printing label), logo segel, dan emboss kulit, yang berkeinginan untuk mendapatkan keuntungan yang jauh lebih besar dengan meningkatkan pemasaran produk. Namun proses bisnis yang saat ini dilaksanakan cukup konvensional, seperti pameran, penjualan telepon, e-mail, dan media promosi lainnya yang berdampak pada tingginya biaya yang dikeluarkan dan dinilai kurang efektif dan efisien. Oleh karena itu, pengembangan web e-commerce pada PT Victoria Label dipandang perlu untuk membantu meningkatkan kemajuan perusahaan, dengan menggunakan model sekuensial Linear dalam perancangan sistem informasi. Hasil dari penelitian ini adalah penerapan e-commerce dengan model B2B dapat mengendalikan proses bisnis dan menghadirkan berbagai efisiensi kegiatan operasional pada perusahaan.
\end{abstract}

\begin{abstract}
Internet causes trading activities to develop, namely by the existence of online product sales, this facility is called e-commerce. PT. Victoria Label is a PMA (Foreign Investment) company engaged in making woven labels and printed labels (printing labels), seal logos, and leather emboss, which are eager to get far greater profits by increasing product marketing. However, the business processes currently being implemented are fairly conventional, such as exhibitions, telephone sales, e-mails, and other promotional media which have an impact on the high costs incurred and are considered to be less effective and efficient. Therefore, e-commerce web development at PT Victoria Label is deemed necessary to help improve the company's progress, using the Linear sequential model in the design of information systems. The results of the research are the application of e-commerce with $B 2 B$ models to control business processes and bring various efficiency of operational activities to the company.
\end{abstract}

Keywords: E-Commerce, B2B, Linear sequential model, system design.

\section{PENDAHULUAN}

Model bisnis e-commerce (B2B, B2C, C2C, C2B, B2G) semakin meroket di tahun 2020. Transaksi dari sektor ini dikalkulasikan mencapai Rp 3000 triliun (US\$ 21 Miliar) pada tahun 2019 atau naik 15 kali lipat dibanding transaksi e-commerce Indonesia pada 2015 yang nilainya $\mathrm{Rp} 200$ triliun (Seni, 2018). Definisi e-commerce menurut Laudon \& Laudon (2009) dalam (Pradana, 2015) adalah suatu proses membeli dan menjual produk-produk secara elektronik oleh konsumen dan dari perusahaan ke perusahaan dengan komputer sebagai perantara transaksi bisnis. E-commerce merupakan salah satu faktor yang penting untuk menunjang keberhasilan suatu produk (Wibowo, 2016) dan menjadi strategi peningkatan jaringan pemasaran.

PT. Victoria Label adalah perusahaan PMA (Penanaman Modal Asing) yang bergerak dalam membuat label tenunan (woven label), label dicetak (printing label), seal logo, dan emboss kulit. Produk yang dibuat pada PT. Victoria Label dapat digunakan sebagai aksesoris garment, sepatu, tas, dan aksesoris lainnya. Dalam pemasaran produknya PT. Victoria Label menempuh beberapa cara guna mendapatkan kerjasama dengan instansi lain sebagai customer nya, yaitu dengan mengikuti pameranpameran di berbagai tempat agar mendapatkan pelanggan baru, yang tentu saja mengeluarkan cost yang tidak sedikit karena harus sewa stand, kedua dengan cara menelepon dan mengirimi email para customer satu persatu untuk menawarkan produk dan jasa pembuatan label serta produk lainnya yang ternyata dinilai masih kurang efektif. Di sisi lain, jumlah pesaing yang semakin bertambah menyebabkan perusahaan semakin sulit menjaga performansi dan kinerja dengan tingkat penjualannya (Prasetya, Witanti, \& Hadiana, 2018). Berdasarkan hal tersebut teknologi memiliki peranan yang sangat penting dalam menjalankan bisnis, khususnya komputer dan internet (Marhamah, Hidayatuloh, \& Irawan, 2016), oleh sebab itu 
penerapan e-commerce dengan model $\mathrm{B} 2 \mathrm{~B}$ dapat dimanfaatkan pada perusahaan untuk mengendalikan proses bisnis (Maidoni, Lestari, \& Putra, 2010). Karena dengan mengadopsi model bisnis $e$ commerce $\mathrm{B} 2 \mathrm{~B}$ akan mendatangkan berbagai efisiensi aktivitas operasional pada perusahaan.

Tujuan penelitian ini adalah membangun sistem informasi berbasis web yang dinamis. Hasil dari pembangunan sistem informasi berbasis web tersebut adalah suatu model bisnis e-commerce $\mathrm{B} 2 \mathrm{~B}$ untuk sistem informasi penjualan produk dan sebagai sistem pemilihan supplier pada PT. Victoria Label. Sejalan dengan kajian penelitian sebelumnya bahwa solusi untuk mengatasi permasalahan yang ada pada bagian penjualan di Tiga Negeri Music House maka dibutuhkan sistem informasi penjualan produk berbasis web (Prasetya et al., 2018).

\section{METODOLOGI PENELITIAN}

Metodologi penelitian yang digunakan adalah:

A. Teknik Pengumpulan data

Teknik pengumpulan data yang dilakukan adalah:

1. Pengamatan (Observation)

Melakukan pengamatan langsung terhadap kegiatan yang berhubungan dengan proses bisnis pada bagian penjualan dan pembelian. Hasil dari kegiatan observasi dapat diketahui sistem yang sedang berjalan pada perusahaan.

2. Wawancara (Interview)

Dilakukan suatu metode tanya jawab dengan kepala bagian penjualan dan pembelian PT. Victoria Label mengenai semua kegiatan yang berhubungan dengan proses bisnis penjualan dan pembelian.

3. Studi Pustaka

Melakukan studi kepustakaan melalui literaturliteratur seperti buku, jurnal, paper yang terkait dengan e-commerce dan model business to business (B2B).

B. Tahapan pengembangan sistem yang digunakan dalam penelitian ini adalah Linier Sequential Model (Waterfall). Sebagai paradigma kehidupan klasik, Linier Sequential Model memiliki tempat penting dalam rekayasa perangkat lunak. Adapun tahapantahapan yang ada dalam paradigma Linier Sequential Model ini digambarkan sebagai berikut:

1. Analisis dan Definisi persyaratan

Menganalisa infomasi yang diperoleh dari berbagai nara sumber kemudian menganalisa data tersebut untuk diolah ditahap berikutnya. Pada tahapan ini kebutuhan diseleksi secara selektif untuk masing-masing pelaku potensial yang terlibat langsung dalam sistem informasi berbasis web model $B 2 B$, pelaku yang terlibat diantaranya administrator, konsumen, dan supplier. Administrator akan bertugas menjalankan dan memelihara sistem (misalnya mencatat semua transaksi yang terjadi dan melayani semua yang dibutuhkan oleh konsumen), konsumen akan mencari kebutuhan yang diinginkan, mengevaluasi alternatif dan transaksi pembelian, sedangkan supplier melakukan pendaftaran untuk menjadi rekanan pada perusahaan.

2. Perancangan Sistem dan Perangkat Lunak Perancangan sistem pembuatan program bertujuan untuk memenuhi keinginan atau kebutuhan pengguna, penerapan proses, masukan dan keluaran, basis data dan tampilan user (GUI) dengan menggunakan Unified Modeling Language (UML) dan Entity Relation Diagram (ERD). Untuk perancangan perangkat lunak penulis menggunakan XAMPP sebagai Web Server, dalam perancangan website ini penulis menggunakan Software Adobe Dreamwever CS6, Adobe Photoshop CS6, Google Chrome dan Mozilla Firefox. Untuk kebutuhan perangkat keras disini penulis menggunakan baik Personal Computer (PC) atau Laptop.

3. Implementasi dan Pengujian Unit

Implementasi dan pengujian unit pada sistem informasi berbasis web model $B 2 B$ pada penelitian yang telah dilakukan dan desain perancangan dari sistem sudah di buat kemudian di implementasikan kedalam perangkat lunak dengan menggunakan pemrograman PHP dan Mysql.

4. Integrasi dan Pengujian Sistem

Pengujian ini ditujukan untuk menguji keterhubungan dari tiap-tiap fungsi perangkat lunak untuk menjamin bahwa persyaratan sistem telah terpenuhi, melalui teknik pengujian perangkat lunak Black-Box-Testing (pengujian kotak hitam).

5. Operasi dan pemeliharaan

Pada tahap ini melakukan operasi dan pemeliharaan mencakup koreksi dari beberapa kesalahan yang tidak ditemukan pada tahapan sebelumnya, tidak menutup kemungkinan sebuah perangkat lunak mengalami perubahan ketika sudah dikirimkan ke user. Perubahan terjadi dikarenakan terdeteksinya kesalahan pada saat dilakukan pengujian sistim atau perangkat lunak harus beradaptasi dengan lingkungan baru. Maka perlu adanya perbaikan atas implementasi unit sistem dan pengembangan pelayanan sistem.

\section{HASIL DAN PEMBAHASAN}

Proses bisnis sistem yang sedang berjalan pada PT. Victoria Label pada saat ini diawali dengan, setelah pelanggan melihat katalog produk dan bagian pemasaran memberikan informasi tentang katalog produk lalu pelanggan memesan produk bisa melalui 
email, telepon, atau datang lansung, setelah itu bagian invoice membuat Purcase Order (PO) pesanan dan bagian stok mengecek stok produk. Bagian invoice akan membuat invoice tagihan dan pelanggan menerima softcopy invoice lalu pelanggan melakukan pembayaran dan menyerahkan bukti transfer. Bagian invoice membuat surat jalan dan menyerahkan invoice kepada bagian pengiriman dan bagian pengiriman mengirim produk kepada pelanggan.

Berikut ini adalah tahapan penelitian yang dilakukan dalam pembangunan web e-commerce $\mathrm{B} 2 \mathrm{~B}$ dengan menggunakan Linear Sequential Model:

A. Analisis Sistem Berjalan

1. Proses bisnis sistem yang sedang berjalan pada PT. Victoria Label:

a) Proses di awali dengan pelanggan melihat katalog produk, kemudian bagian pemasaran memberikan informasi tentang produk kepada pelanggan.

b) Pelanggan memesan produk melalui Bagian Pemasaran dengan cara kirim email, telepon, atau datang lansung ke perusahaan.
Kemudian bagian Pemasaran akan membuatkan Purcase Order (PO).

c) Berdasarkan Purcase Order (PO) dari bagian Pemasaran maka Bagian invoice akan membuat invoice tagihan dan mengirimkan kepada pelanggan.

d) Pelanggan melakukan pembayaran dan menyerahkan bukti transfer kepada bagian Invoice. Bagian invoice mengkonfirmasi pembayaran ke Bagian Keuangan untuk divalidasi.

e) Setelah pembayaran divalidasi maka Bagian Invoice membuatkan Surat Jalan yang kemudian diberikan ke Bagian Pengiriman beserta Invoice nya untuk dilakukan pengiriman pesanan.

f) Bagian pengiriman mengirim produk kepada pelanggan dan menyerahkan invoice asli serta copy surat jalan.

2. Activity Diagram

Proses bisnis sistem berjalan yang terjadi saat ini pada PT Vitoria Label digambarkan dengan Activity diagram sebagai berikut:

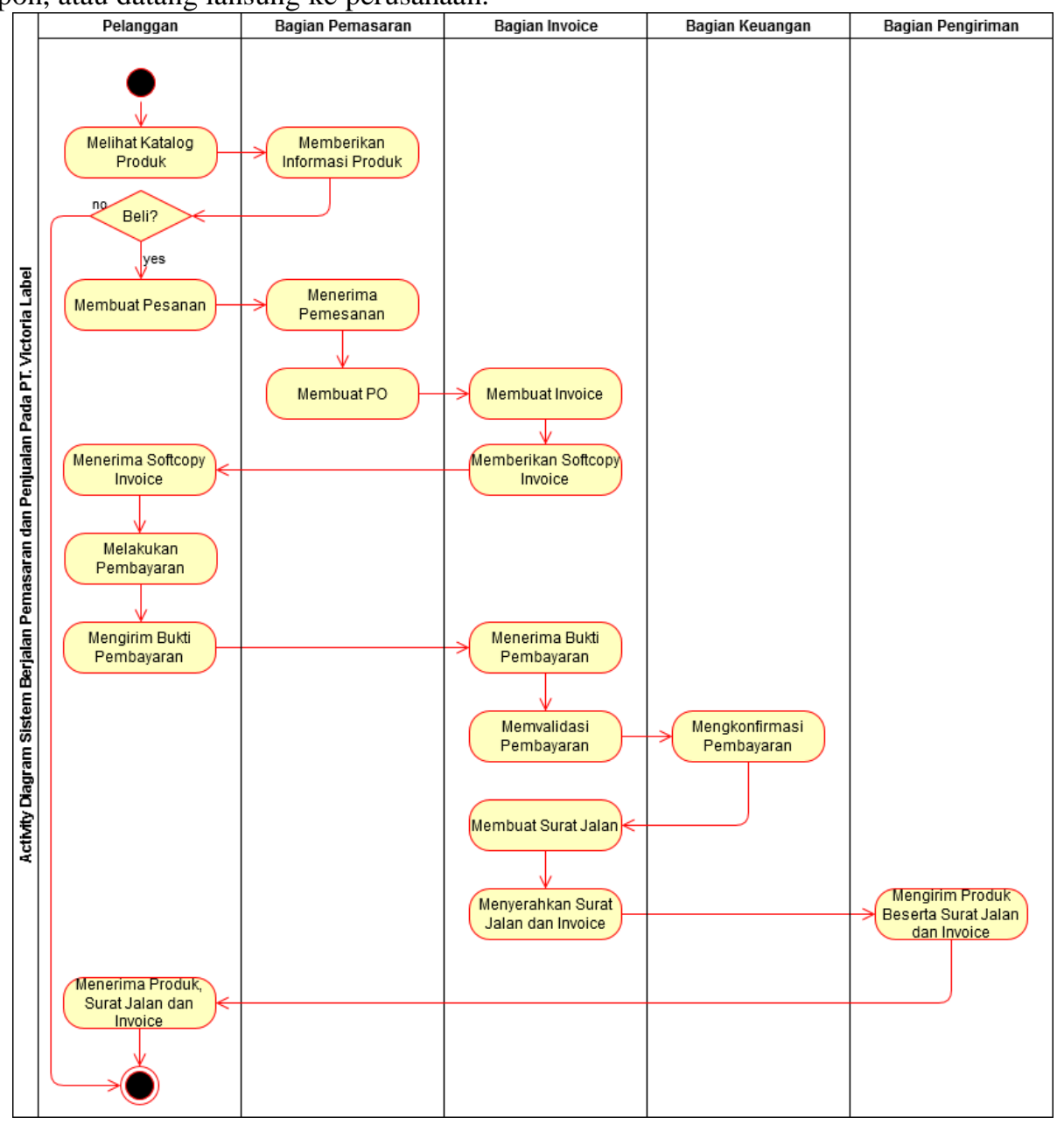

Gambar 1. Activity Diagram Sistem Berjalan Pemasaran dan Penjualan PT. Victoria Label

Pada Gambar 1 jelas terlihat bahwa PT. Victoria Label melakukan pemasaran dan Penjualan secara manual, dimana bagian pemasaran bertemu langsung dengan pelanggan untuk penjelaskan mengenai produk yang dijual nya. Dan proses pemesanan juga masih menggunakan email/telepon/datang langsung 
yang tentunya sangat tidak efisien dalam pengerjaannya sedangkan data masih menggunakan dokumen cetakan yang mungkin saja dapat terjadi kerusakan atau kehilangan.

B. Perancangan Sistem dan Perangkat Lunak

1. Analisa kebutuhan software

Tahapan ini menjelaskan tentang kebutuhan fungsional (software dapat melakukan apa saja), disertai dengan penggambaran use case diagram dan activity diagram yang terkait dengan proses bisnis.

a. Tahapan analisa

Proses bisnis yang di usulkan untuk sistem penjualan kepada pelanggan:

1) Registrasi pelanggan

2) Login ke dalam website

3) Memilih Produk

4) Checkout

5) Melakukan pembayaran

6) Melakukan konfirmasi pembayaran

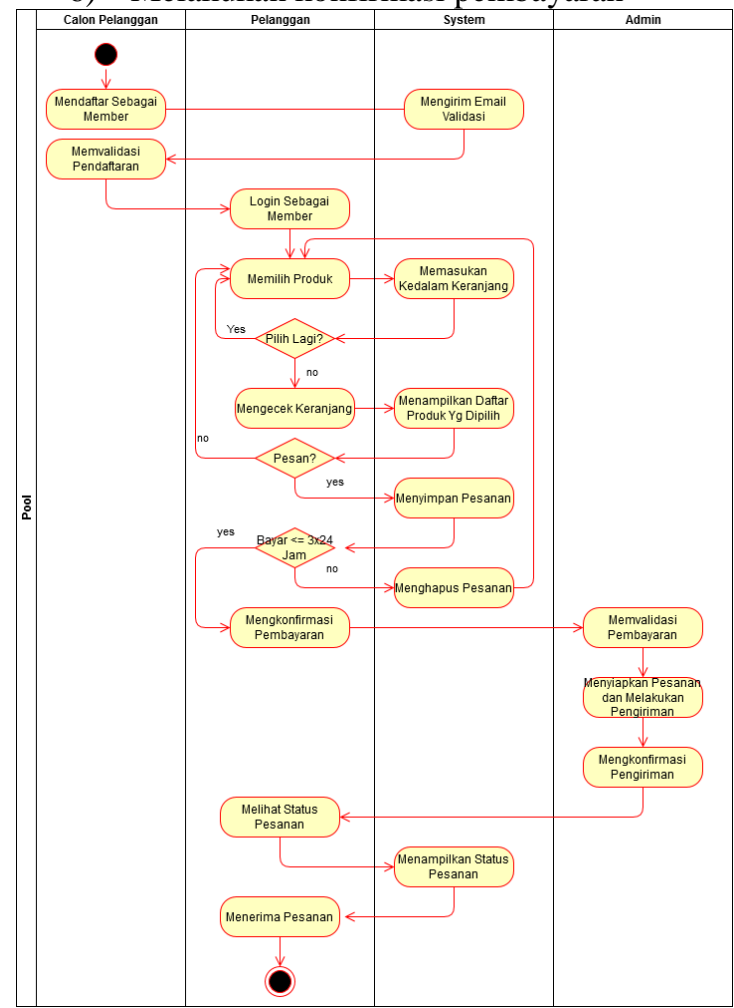

Gambar 2. Activity diagram proses bisnis sistem penjualan usulan

Pada activity diagram proses bisnis penjualan usulan dapat terlihat jelas jika system usulan yang baru lebih bernilai efisien tenaga, waktu dan biaya dikarenakan kita dapat memangkas proses yang dilakukan oleh bagian pemasaran dengan menampilkan detail produk dalam website selain itu data langsung dapat terdistribusi ke bagian yang terkait tanpa melakukan pengiriman dokumen atau melakukan konfirmasi melalui telepon lagi.
Data yang diproses juga sudah terfilter melalui sistem dimana jika pelanggan tidak melakukan pembayaran sesuai dengan batas waktu yang ditentukan maka pesanan akan otomatis dibatalkan dan admin hanya memproses pesanan yang terkonfirmasi dan validasi pembayarannya saja. Selain itu data yang ada jelas dapat tersimpan lebih aman dan tidak memakan biaya dan tempat yang banyak seperti pada sistem berjalan sebelumnya.

b. Use case digram

1) Use case diagram asosiasi antara actor dan use case sistem penjualan

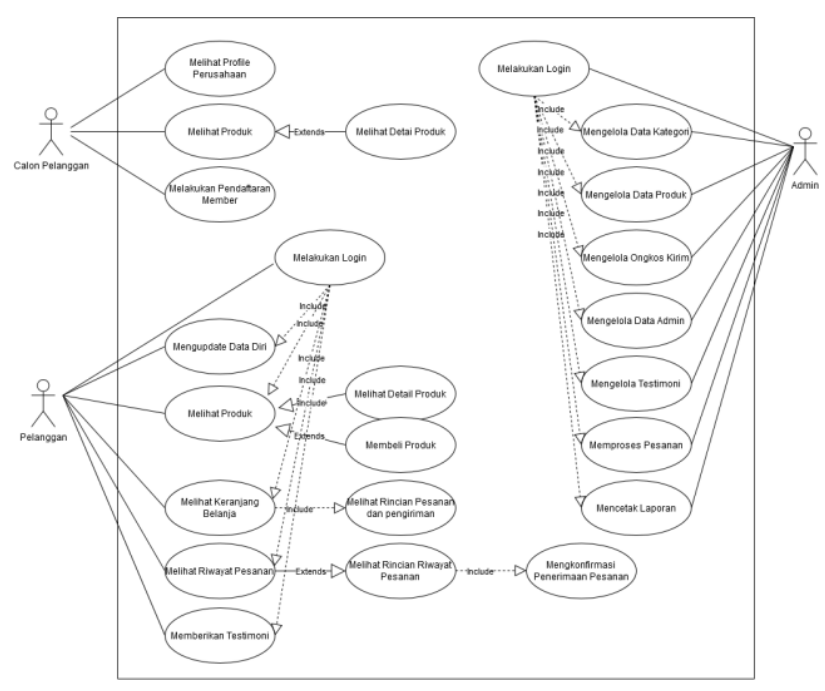

Gambar 3. Use case diagram sistem penjualan

Pada Gambar 3 yaitu Use Case diagram sistem penjualan yang diusulkan dapat terlihat gambaran dari sistem penjualan yang baru menggunakan website E-Commerce dimana setiap actor memiliki hak yang berbeda, hal ini merupakan salah satu bagian dari sisi keamanan dari sistem Web ECommerce.

Sistem ini tentunya tidak hanya dapat digunakan untuk melakukan proses transaksi penjualan tetapo juga dapat digunakan sebagai media promosi untuk perusahaan dalam mengenalkan perusahaan dan juga produknya ke masyarakat serta dapat membangun kepercayaan masyarakat terhadap perusahaan

2. Desain

Pada tahap ini akan menjelaskan tentang desain database, software architecture dan user interface dari sistem usulan pada Web ECommerce

a. Database

1) Entity Relationship Diagram (ERD) 


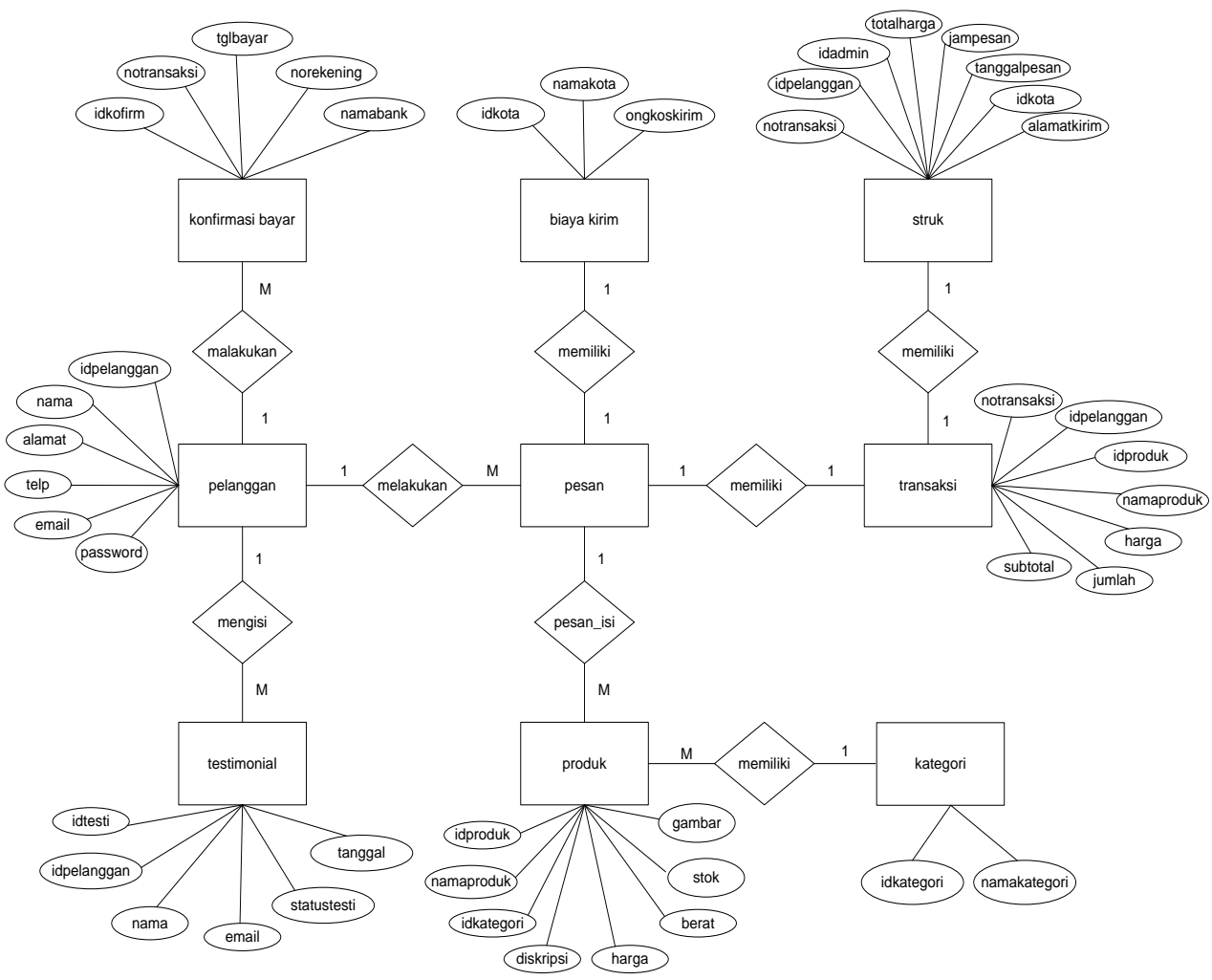

Gambar 4. ERD Sistem Penjualan

\section{2) Logical Record System (LRS)}

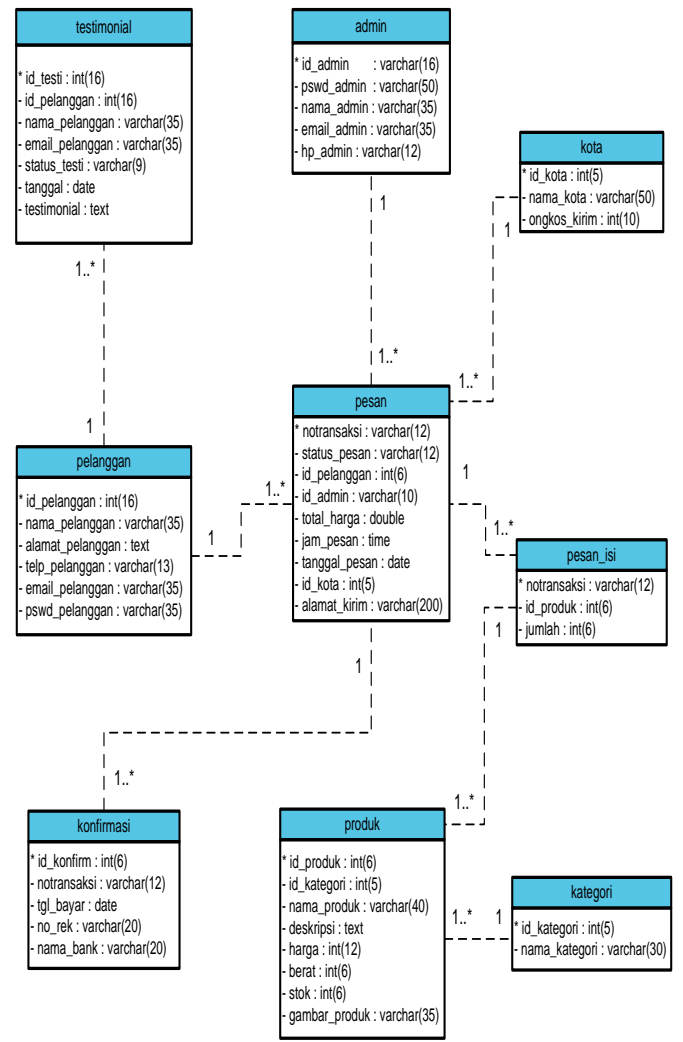

Gambar 5. LRS penjualan b. Rancangan Database

Dalam perancangan sistem informasi berbasis web ini, menggunakan satu database, dengan spesifikasi file:

Tabel 1. Tabel admin

\begin{tabular}{lllll}
\hline Elemen data & Nama field & Type & Size & Ket \\
\hline Id admin & id_admin & varchar & 9 & PK \\
\hline Password & pswd_admin & varchar & 35 & \\
\hline Nama admin & nama_admin & varchar & 35 & \\
\hline Email admin & email_admin & varchar & 35 & \\
\hline Hp admin & hp_admin & varchar & 13 & \\
\hline
\end{tabular}

Tabel 2.Tabel Pelanggan

\begin{tabular}{lllll}
\hline Elemen data & Nama field & Type & Size & Ket \\
\hline Id pelanggan & id_pelanggan & Int & 4 & PK \\
\hline Nama & nama_pelanggan & varchar & 35 & \\
\hline Alamat & alamat_pelanggan & Text & & \\
\hline Telepon & telp_pelanggan & varchar & 13 & \\
\hline Email & email_pelanggan & varchar & 35 & \\
\hline
\end{tabular}

Tabel 3. Tabel Kota

\begin{tabular}{lllll}
\hline Elemen data & Nama field & Type & Size & Ket \\
\hline Id kota & id_kota & Int & 3 & PK \\
\hline Nama kota & nama_kota & varchar & 50 & \\
\hline Ongkos kirim & ongkos_kirim & Int & 10 &
\end{tabular}

Tabel 4. Tabel Kategori

\begin{tabular}{lllll}
\hline Elemen data & Nama field & Type & Size & Ket \\
\hline Id kategori & id_kategori & Int & 5 & PK \\
\hline Nama kategori & nama_kategori & varchar & 30 & \\
\hline
\end{tabular}


Paradigma - Jurnal Informatika dan Komputer,

Vol. 22, No. 2September 2020

P-ISSN 1410-5063, E-ISSN: 2579-3500

Tabel 5. Tabel Produk

\begin{tabular}{lllll}
\hline Elemen data & Nama field & Type & Size & Ket \\
\hline Id produk & id_produk & Int & 6 & PK \\
\hline Id kategori & id_kategori & Int & 5 & \\
\hline Nama produk & nama_produk & Varchar & 40 & \\
\hline Deskripsi & deskripsi & Text & & \\
\hline Harga & Harga & Int & 8 & \\
\hline Berat & Berat & Int & 6 & \\
\hline Stok & Stok & Int & 6 & \\
\hline Gambar & gambar_produk & Varchar & 35 & \\
\hline
\end{tabular}

Tabel 6. Tabel pesan isi

\begin{tabular}{lllll}
\hline Elemen data & Nama field & Type & Size & Ket \\
\hline Notransaksi & notransaksi & Int & 12 & PK \\
\hline Id produk & id_produk & Int & 6 & \\
\hline Jumlah & jumlah & Int & 6 & \\
\hline
\end{tabular}

Tabel 7. Tabel pesan

\begin{tabular}{lllll}
\hline Elemen data & Nama field & Type & Size & Ket \\
\hline Notransaksi & notransaksi & Varchar & 12 & PK \\
\hline Status pesan & status_pesan & Varchar & 12 & \\
\hline Id pelanggan & id_pelanggan & Int & 4 & \\
\hline Id admin & id_admin & Varchar & 9 & \\
\hline Total Harga & total_harga & Int & 8 & \\
\hline Jam pesan & jam_pesan & Time & & \\
\hline Tanggal pesan & tanggal_pesan & Date & & \\
\hline Id kota & id_kota & Int & 3 & \\
\hline Alamat kirim & alamat_kirim & Varchar & 200 & \\
\hline
\end{tabular}

Tabel 8. Tabel konfirmasi

\begin{tabular}{lllll}
\hline Elemen data & Nama field & Type & Size & Ket \\
\hline Id konfirmasi & id_konfirm & Int & 5 & PK \\
\hline Notransaksi & notransaksi & Varchar & 12 & \\
\hline Tanggal bayar & tgl_bayar & Date & 0 & \\
\hline
\end{tabular}

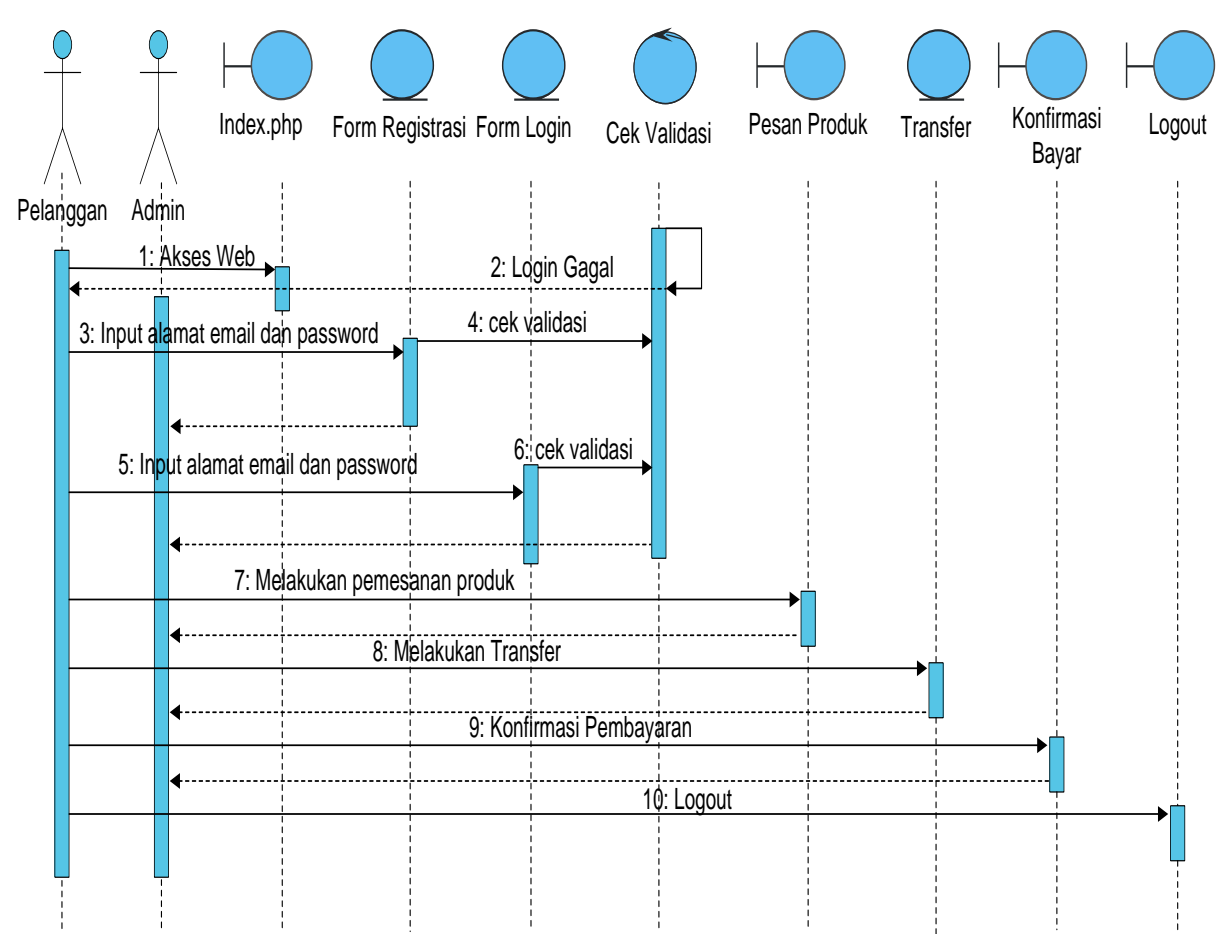

Gambar 6. Sequence Diagram Penjualan Online

Tabel 9. Tabel testimoni

\section{Software Architecture} saja).

a. Sequence diagram penjualan online online.

\begin{tabular}{lllll}
\hline Elemen data & Nama field & Type & Size & Ket \\
\hline Id Testimonial & id_testi & int & 4 & PK \\
\hline Id Pelanggan & id_pelanggan & varchar & 4 & \\
\hline Id Admin & id_admin & varchar & 9 & \\
\hline Satus Testi & status_testi & varchar & 9 & \\
\hline Tanggal Buat & Tanggal & date & & \\
\hline Testimonial & Testimonial & text & & \\
\hline
\end{tabular}

Pada tahapan software architecture menggambarkan, sequence diagram, class diagram, component diagram, dan deployment diagram (terkait dengan program yang di buat dan yang hanya berhubungan dengan proses bisnis sistem

Pada tahapan ini menggambarkan pelanggan yang mengakses website PT. Victoria Label. Pada saat melakukan login pelanggan terdapat validasi yang akan menolak jika pelanggan memasukan username dan password yang salah. Setelah login berhasil, maka pelanggan dapat melakukan pemesanan produk, melakukan pembayaran jumlah total pembelanjaan melalui transfer bank yang tertera di website PT. Victoria Label dan melakukan konfirmasi pembayaran. Pelanggan dapat keluar dari sistem penjualan secara 
Paradigma - Jurnal Informatika dan Komputer,

Vol. 22, No. 2September 2020

P-ISSN 1410-5063, E-ISSN: 2579-3500

b. Class diagram

Class diagram atau kelas diagram

pendefinisian kelas-kelas yang akan dibuat menggambarkan struktur sistem dari segi

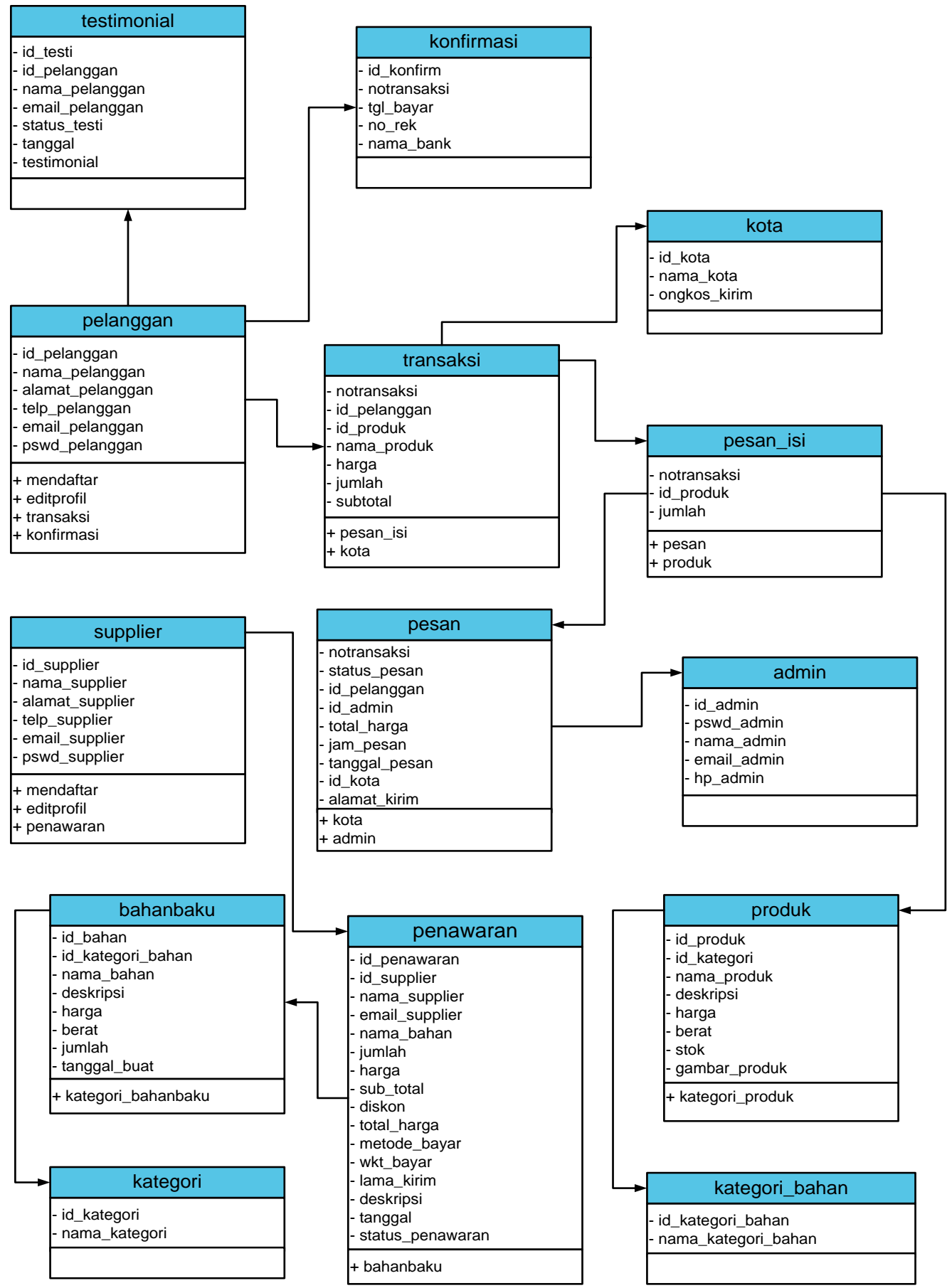

Gambar 7. Class Diagram Sistem Penjualan dan Pemilihan Supplier

c. Component diagram

Component diagram atau diagram komponen dibuat untuk menunjukan organisasi dan ketergantungan diantara kumpulan komponen dalam sebuah system. 
Paradigma - Jurnal Informatika dan Komputer,

Vol. 22, No. 2September 2020

P-ISSN 1410-5063, E-ISSN: 2579-3500

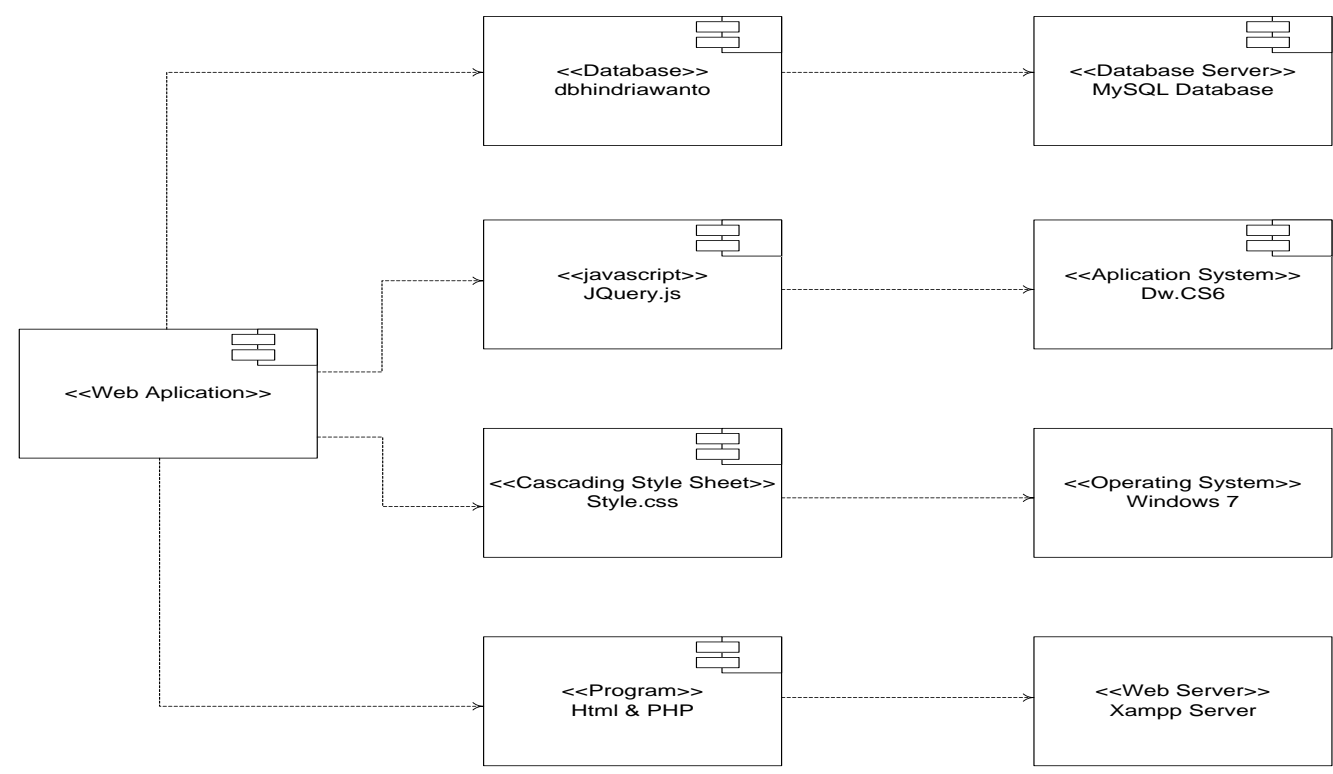

Gambar 13. Component diagram

\section{d. Deployment diagram}

Deployment diagram atau diagram deployment dibuat untuk menunjukan komponen dalam proses eksekusi aplikasi.

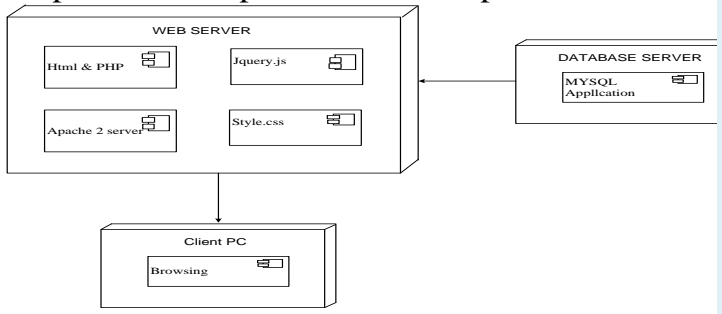

Gambar 14. Deployment diagram

C. Implementasi

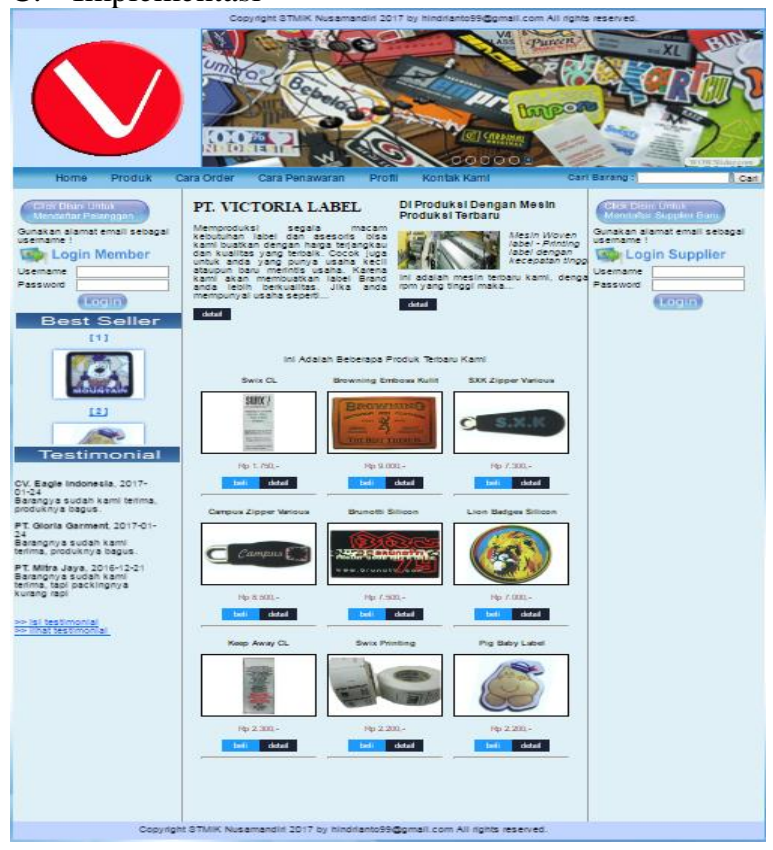

Gambar 15. Halaman utama pengunjung

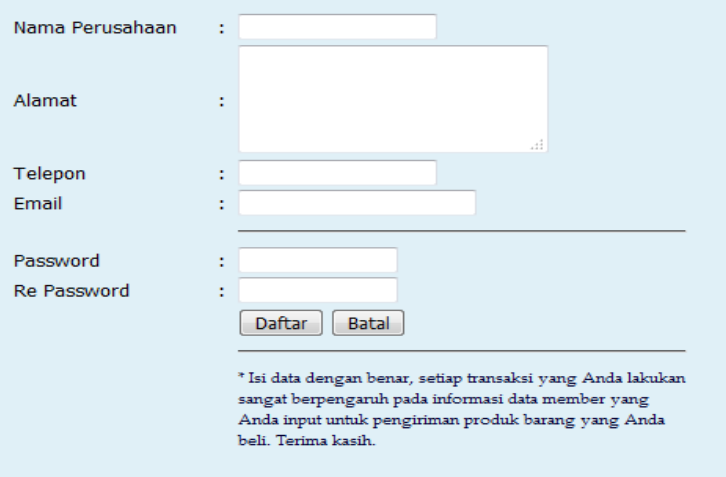

Gambar 16. Registrasi pelanggan

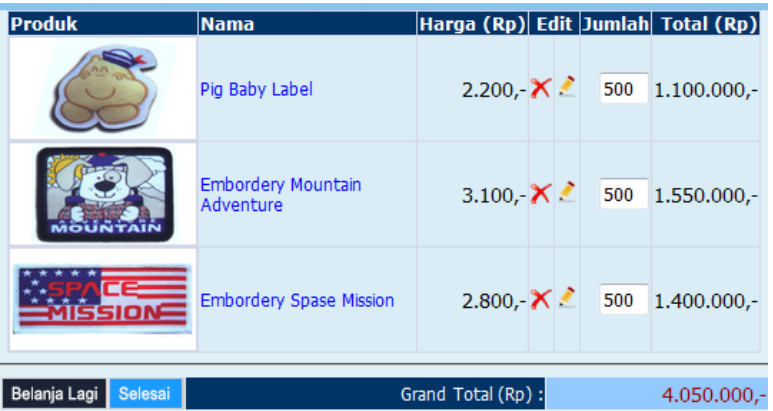

Gambar 17. Halaman keranjang belanja

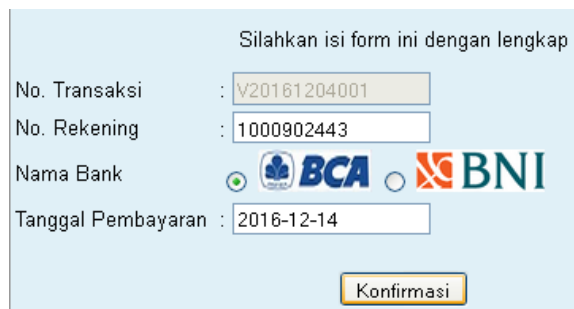

*) Setelah melakukan pembayaran, harap segera menghubungi kami untuk konfirmasi agar pesanan Anda dapat segera di PROSES.

Gambar 18. Konfirmasi pembayaran 


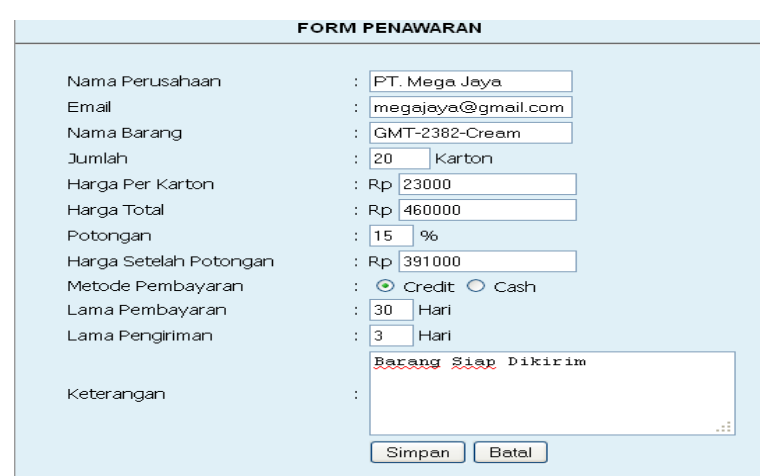

Gambar 19. Form penawaran

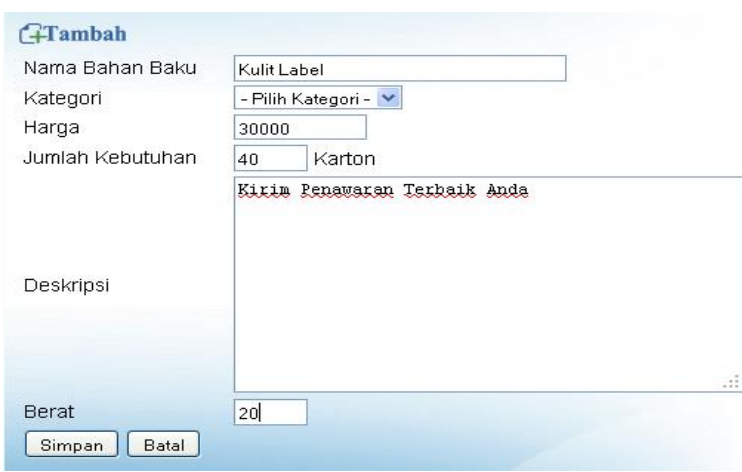

Gambar 20. Halaman input rencana kebutuhan

D. Pengujian Sistem

Black-Box-Testing (pengujian kotak hitam) yaitu menguji perangkat lunak dari segi spesifikasi fungsional tanpa menguji desain dan kode program. Tujuan dari pengujian adalah untuk mengecek apakah program yang dibuat sudah sesuai dengan spesifikasi yang dibutuhkan dan mengetahui bahwa sistem dapat menangani kesalahan yang pengguna lakukan.

Tabel 15. Kesimpulan Hasil Pengujian Black Box

\begin{tabular}{lcccc}
\hline Pengujian & $\begin{array}{c}\text { Validasi } \\
\text { data } \\
\text { kosong }\end{array}$ & $\begin{array}{c}\text { Validasi } \\
\text { data } \\
\text { salah }\end{array}$ & $\begin{array}{c}\text { Validasi } \\
\text { data } \\
\text { benar }\end{array}$ & $\begin{array}{c}\text { Validasi } \\
\text { data } \\
\text { sama }\end{array}$ \\
\hline Form pendaftaran & $\checkmark$ & $\checkmark$ & $\checkmark$ & $\checkmark$ \\
\hline Login pelanggan & $\checkmark$ & $\checkmark$ & $\checkmark$ & - \\
\hline Login supplier & $\checkmark$ & $\checkmark$ & $\checkmark$ & - \\
\hline Login admin & $\checkmark$ & $\checkmark$ & $\checkmark$ & - \\
\hline $\begin{array}{l}\text { Konfirmasi } \\
\text { pembayaran }\end{array}$ & $\checkmark$ & - & - & - \\
\hline Form penawaran & $\checkmark$ & - & - & - \\
\hline Tambah admin & $\checkmark$ & - & - & - \\
\hline Tambah kategori & $\checkmark$ & - & - & - \\
\hline Tambah produk & $\checkmark$ & - & - & - \\
\hline $\begin{array}{l}\text { Tambah } \\
\text { kirim }\end{array}$ & $\checkmark$ & - & - & - \\
\hline $\begin{array}{l}\text { Rencana } \\
\text { kebutuhan admin }\end{array}$ & & & & - \\
\hline Input testimoni & $\checkmark$ & - & - & - \\
\hline
\end{tabular}

E. Support

Setelah seluruh website selesai dibangun, hal terpenting adalah bagaimana agar semua orang dapat mengakses website itu sendiri. Publikasi sistem informasi berbasis web dengan model $B 2 B$ ini melalui sebuah penyedia jasa hosting gratis pada https://www.hostinger.co.id/free-domain dengan alamat website adalah http://e-hindriawanto.hol.es

\section{KESIMPULAN}

Penelitian ini menghasilkan sistem informasi berbasis web dengan model $B 2 B$ yang dapat membantu PT. Victoria Label dalam meningkatkan pelayanan dan penjualan di berbagai wilayah baik dalam kota maupun luar kota. Sistem dapat memperbaiki efektivitas dan efisiensi yang memudahkan pada bagian marketing PT. Victoria Label dalam memperkenalkan produk baru dan memberikan informasi mengenai produk dan pemesanan produk kepada pelanggan. Sistem informasi berbasis web dengan model $B 2 B$ juga ini dapat menciptakan integrasi antara konsumen dengan perusahaan dan supplier dengan perusahaan, sehingga dapat mempermudah supplier untuk mendaftar sebagai rekan bisnis pada PT. Victoria Label.

Pada penelitian selanjutnya yang bersumber pada penelitian ini dapat dikembangkan dengan menambahkan informasi persedian agar integrasi antara supplier dengan perusahaan dalam perencanaan kebutuhan bahan baku dapat dikendalikan.

\section{REFERENSI}

Maidoni, F., Lestari, E., \& Putra, A. (2010). Penerapan Model B2B Pada Sistem Informasi Berbasis Web (Studi Kasus PT Semen Baturaja Persero). Jurnal Sistem Informasi, 2(1), 206-219.

Marhamah, Hidayatuloh, S., \& Irawan, A. (2016). Sistem E-Commerce B2C Pada PT Harapan Sentosa Nusantara Jakarta Pusat. Jurnal Sistem Informasi, 9(2), 159-167.

Pradana, M. (2015). KLASIFIKASI JENIS-JENIS BISNIS E-COMMERCE. Jurnal Neo-Bis, 9(2), 32-40.

Prasetya, M. R., Witanti, W., \& Hadiana, A. I. (2018). Sistem Informasi Penjualan Corporate Business To Customer ( B2C ) Dan Business To Business ( B2B ) Produk Pada Tiga Negeri Music House Bandung. In Seminar Nasional Teknologi Informasi dan Multimedia 2018 (pp. 109-114). Yogyakarta.

Seni, S. (2018). 5 Model Bisnis eCommerce (B2B, B2C, C2C, C2B, B2G) 2020. Retrieved February 12, 2020, from https://www.softwareseni.co.id/5-modelbisnis-ecommerce-b2b-b2c-c2c-c2b-b2g/

Wibowo, E. A. (2016). Pemanfaatan Teknologi ECommerce Dalam Proses Bisnis. Equilibiria, 1(1), 95-108. Retrieved from http://journal.unrika.ac.id/index.php/equi/articl e/view/222 
Paradigma - Jurnal Informatika dan Komputer,

Vol. 22, No. 2September 2020

P-ISSN 1410-5063, E-ISSN: 2579-3500

A.M Hirin, Virgi. 2011. Cepat Mahir Pemrograman Web Dengan Php dan MySql. Jakarta: Prestasi Pustaka.

Ahmadi, Hermawan. 2013. E-Business \& ECommerce. Yogyakarta: Andi Offset.

Anhar. 2010. Panduan Menguasai Php dan MySql Secara Otodidak. Jakarta: Mediakita.
Bambang Hartono. 2013. Sistem Informasi Manajemen Berbasis Komputer. Jakarta: Rineka Cipta.

Rossa A.S, M.Shalahuddin. 2015. Rekayasa Perangkat Lunak Tersturktur dan Berorientasi Objek Bandung: Informatika. 